University of Nebraska - Lincoln

DigitalCommons@University of Nebraska - Lincoln

John R. Hardy Papers

Research Papers in Physics and Astronomy

3-2002

\title{
Polymorphous Transformations in Alkaline-Earth Silicates
}

\author{
Jianjun Liu \\ University of Nebraska - Lincoln \\ Chun-Gang Duan \\ University of Nebraska at Omaha, cgduan@clpm.ecnu.edu.cn \\ Wai-Ning Mei \\ University of Nebraska at Omaha, physmei@unomaha.edu \\ R. W. Smith \\ University of Nebraska at Omaha, robertsmith@unomaha.edu \\ John R. Hardy \\ University of Nebraska - Lincoln
}

Follow this and additional works at: https://digitalcommons.unl.edu/physicshardy

Part of the Physics Commons

Liu, Jianjun; Duan, Chun-Gang; Mei, Wai-Ning; Smith, R. W.; and Hardy, John R., "Polymorphous Transformations in Alkaline-Earth Silicates" (2002). John R. Hardy Papers. 2.

https://digitalcommons.unl.edu/physicshardy/2

This Article is brought to you for free and open access by the Research Papers in Physics and Astronomy at DigitalCommons@University of Nebraska - Lincoln. It has been accepted for inclusion in John R. Hardy Papers by an authorized administrator of DigitalCommons@University of Nebraska - Lincoln. 


\title{
Polymorphous transformations in alkaline-earth silicates
}

\author{
Jianjun Liu \\ Department of Physics and Center for Electro-Optics, University of Nebraska, Lincoln, \\ Nebraska 68588-0111 and Department of Physics, University of Nebraska, Omaha, Nebraska 68182-0266 \\ Chun-gang Duan and W. N. Mei \\ Department of Physics, University of Nebraska, Omaha, Nebraska 68182-0266
}

R. W. Smith

Department of Chemistry, University of Nebraska, Omaha, Nebraska 68182-0109

J. R. Hardy

Department of Physics and Center for Electro-Optics, University of Nebraska, Lincoln, Nebraska 68588-0111

(Received 20 September 2001; accepted 3 December 2001)

\begin{abstract}
Structural phase transitions in $\mathrm{Ca}_{2} \mathrm{SiO}_{4}$ and $\mathrm{Sr}_{2} \mathrm{SiO}_{4}$ are investigated by molecular dynamics simulations. The simulations are based on the potentials calculated from the Gordon-Kim modified electron gas formalism extended to molecular ions. We successfully reproduced the transition $\gamma$ $-\alpha_{H}^{\prime}-\alpha$ and $\beta-\alpha_{L}^{\prime}-\alpha_{H}^{\prime}-\alpha$ in $\mathrm{Ca}_{2} \mathrm{SiO}_{4}$, and the transition $\beta-\alpha^{\prime}$ in $\mathrm{Sr}_{2} \mathrm{SiO}_{4}$. We find that the $\alpha_{L}^{\prime}$ phase of $\mathrm{Ca}_{2} \mathrm{SiO}_{4}$ is an $a \times 3 b \times c$ superstructure of the $\alpha_{H}^{\prime}$ phase, while the $\alpha_{H}^{\prime}$ phase has a $\beta-\mathrm{K}_{2} \mathrm{SO}_{4}$ structure, and the $\alpha$ phase of $\mathrm{Ca}_{2} \mathrm{SiO}_{4}$ has a disordered structure with space group $\mathrm{Pb}_{3} / \mathrm{mmc}$. (ㅇ 2002 American Institute of Physics. [DOI: 10.1063/1.1446043]
\end{abstract}

\section{INTRODUCTION}

There are at least five phases $\beta, \gamma, \alpha_{L}^{\prime}, \alpha_{H}^{\prime}$, and $\alpha$ of $\mathrm{Ca}_{2} \mathrm{SiO}_{4}$ at ambient pressure. The transitions between these five phases have been extensively studied because $\mathrm{Ca}_{2} \mathrm{SiO}_{4}$ is one of the most important constituents of portland cement clinker. ${ }^{1}$ However, some questions still remain about its polymorphism and the nature of its phase transformations occurring with increasing temperature.

The sequence of phase transformations generally accepted is shown in Fig. 1. The $\gamma$ phase has an orthorhombic olivine-type structure and is thermodynamically stable at room temperature. ${ }^{2}$ The $\beta$ phase is a metastable monoclinic phase under ambient conditions and is obtained from the high temperature $\alpha_{L}^{\prime}$ phase on cooling. ${ }^{3}$ The orthorhombic $\alpha_{L}^{\prime}$ phase is generally considered to be a superstructure of the orthorhombic $\alpha_{H}^{\prime}$ phase, but two different possibilities have been proposed. First the $\alpha_{L}^{\prime}$ phase involves a doubling the $a$ and $c$ parameters of the $\alpha_{H}^{\prime}$ phase. ${ }^{4}$ The second possibility consists of a tripling the $b$ parameter of the $\alpha_{H}^{\prime}$ phase. ${ }^{5,6}$ The $\alpha_{H}^{\prime}$ phase is thought to be a $\beta-\mathrm{K}_{2} \mathrm{SiO}_{4}$ structure, while the structure of the $\alpha$ phase is still uncertain and is suggested to have either trigonal ${ }^{7}$ or hexagonal symmetry. ${ }^{8}$

At room temperature, $\mathrm{Sr}_{2} \mathrm{SiO}_{4}$ has a monoclinic structure, the $\beta$ phase, ${ }^{9}$ isostructural with the $\beta$ phase of $\mathrm{Ca}_{2} \mathrm{SiO}_{4}$. It transforms to a high temperature $\alpha_{H}^{\prime}$ phase via the incommensurately modulated $\alpha_{L}^{\prime}$ phase: ${ }^{10} \beta \underline{363 K} \alpha_{L}^{\prime} \frac{773 K}{} \alpha_{H}^{\prime}$. The intervening incommensurate $\alpha_{L}^{\prime}$ phase has been observed in electron-diffraction experiments by the appearance of two sets of satellite Bragg reflections with wave vectors $\mathbf{q}_{1}$ $=0.303 \mathbf{b}^{*}$ and $\mathbf{q}_{2}=0.396 \mathbf{b}^{*}$, where $\mathbf{q}_{2}$ is a second harmonic of $\mathbf{q}_{1} .{ }^{10}$ The $\alpha_{H}^{\prime}$ phase has been determined to have a $\beta-\mathrm{K}_{2} \mathrm{SO}_{4}$ structure. ${ }^{9}$ It was also suggested that there is a third, higher-temperature transition to a hexagonal phase $\alpha$ form with $b$ parallel to the hexagonal $c$ axis. ${ }^{10}$

In this paper we study the phase transitions in $\mathrm{Ca}_{2} \mathrm{SiO}_{4}$ and $\mathrm{Sr}_{2} \mathrm{SiO}_{4}$ by molecular dynamics simulations, using potentials calculated from the Gordon-Kim modified electron gas formalism, ${ }^{11}$ extended to molecular ions. ${ }^{12}$ Our method starts from quantum-chemistry calculations of the whole $\mathrm{SiO}_{4}$ molecular ion to obtain the optimized structure and the electron charge distribution, then, describes the covalent intramolecular interactions using Taylor expansion of the molecular ion's energy, and calculates the ionic intermolecular interactions using the Gordon-Kim electron gas model.

\section{INTER- AND INTRAMOLECULAR POTENTIALS AND STATIC RELAXATION}

A full description of the procedure for obtaining both inter- and intramolecular interaction potentials has been given elsewhere. ${ }^{12}$ Here we outline the main steps.

As a first approximation, we assume that the intramolecular interactions of the $\mathrm{SiO}_{4}$ ion in crystals are the same as those of isolated $\mathrm{SiO}_{4}$ ion. We first performed a quantumchemistry structural optimization for the isolated $\mathrm{SiO}_{4}$ ion using GAUSSIAN94 commercial package, ${ }^{13}$ which searches for the atomic configuration that gives the lowest self-consistent Hartree-Fock energy. Berny algorithm ${ }^{14}$ and standard $6-31 \mathrm{G}^{* *}$ basis set for $\mathrm{Si}$ and $\mathrm{O}$ atoms were used in the $a b$ initio Hartree-Fock calculation. At the optimized configuration, the force constants were computed by determining the second derivatives of the energy with respect to distortions from this optimized structure. With these second derivatives, a harmonic expansion of the energy of the isolated $\mathrm{SiO}_{4}$ ion can be constructed in terms of its bond lengths, bond angles, 


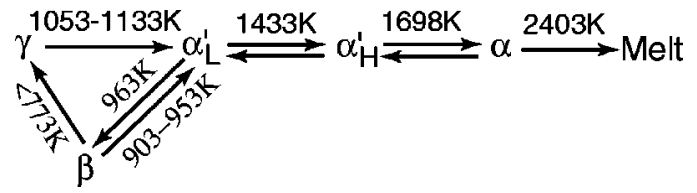

FIG. 1. Sequence of phase transformation in $\mathrm{Ca}_{2} \mathrm{SiO}_{4}$; after Remy (Ref. 1).

and dihedral angles. This harmonic expansion was used to describe the intramolecular interactions, i.e., the $\mathrm{Si}-\mathrm{O}$ and $\mathrm{O}-\mathrm{O}$ interactions within the same $\mathrm{SiO}_{4}$ ion.

The numerical short-range pair potentials between different $\mathrm{SiO}_{4}$ ions, and between alkaline-earth ions and $\mathrm{SiO}_{4}$ ions were calculated according to the Gordon-Kim electron gas model. ${ }^{11}$ The charge densities of silicon and oxygen atoms were extracted from the charge density of the whole isolated $\mathrm{SiO}_{4}$ ion obtained in the self-consistent Hartree-Fock calculation for the optimized structure of $\mathrm{SiO}_{4}$ ion. This extraction was made in the spirit of Mulliken population analysis. ${ }^{15}$ The tabulated charge densities of $\mathrm{Ca}^{+2}$ were used, ${ }^{16}$ while those for $\mathrm{Sr}^{+2}$ were calculated with the software of Liberman et $a l .{ }^{17}$ The numerical short-range potentials were then fitted to the analytic form $U(r)=e^{-\alpha r} \sum_{n=0}^{N} C_{n} r^{m+n}, r_{c}<r<r_{t}$, with $r_{c}=2$ atomic unit (a.u.), $r_{t}=12$ a.u., $N=8$. To complete the fit, a core function $U(r)=A+B / r^{6}, r \leqslant r_{c}$, and a tail function $U(r)=D e^{-\beta r^{2}}, r \geqslant r_{t}$, were attached by requiring that the potential and its first derivative be continuous at the points of attachment.

The long-range Coulomb interactions were calculated using fractional charges of the $\mathrm{Si}$ and $\mathrm{O}$ atoms: specifically, 1.180 for $\mathrm{Si}$ and -1.095 for $\mathrm{O}$. The ionic charge for the alkaline-earth ions is +1.6 . We first attempted to calculate the long-range Coulomb interactions and to simulate phase transitions using the full Mulliken charges of Si and O (1.180 and -1.295$)$ and the full ionic charge of +2 for the cation ions. However, this produced transition temperatures $T_{c}$ that were twice the observed values and lattice constants that were $5 \%$ too small. Reducing the cation charge to +1.6 and decreasing the $\mathrm{O}$ charge to -1.095 enabled us to fit $T_{c}$ for transitions while producing the lattice parameters within $1 \%$ of experiment. This suggests a degree of covalency. However, since the charge transfer is a small fraction of the total outer shell charge ( 0.4 out of 8 for the $\mathrm{Ca}$ ion) we assumed the Gordon-Kim potentials were unchanged.

Using the intramolecular and intermolecular ionic interaction potentials obtained above, we performed static relaxation calculations for the $\gamma$ and $\beta$ phases of $\mathrm{Ca}_{2} \mathrm{SiO}_{4}$ and the $\beta$ phase of $\mathrm{Sr}_{2} \mathrm{SiO}_{4}$ with space group symmetry constraints. These relaxations gave the crystal structures that are at extremes of the theoretical potential-energy surface, where the forces on the ions and the stresses are zero. The minimization was for an infinite lattice, obtained by applying periodic conditions, and followed a Newton-Raphson algorithm. The standard technique of the Ewald sum ${ }^{18}$ was used for the calculation of the lattice energy and forces, etc.

The parameters for the relaxed structures of the $\gamma$ and $\beta$ phases of $\mathrm{Ca}_{2} \mathrm{SiO}_{4}$ and the $\beta$ phase of $\mathrm{Sr}_{2} \mathrm{SiO}_{4}$, along with the room temperature experimental values ${ }^{2,3,9}$ are given in Table I. From this table, one can see that our relaxed structures are in good agreement with experiment. Overall comparison of relaxed structures and experimental structures provides a sensitive test of the validity of the theoretical potential-energy surfaces. The good agreement of our relaxed structures with the experimental structures indicates

TABLE I. Theoretical relaxed structural parameters of $\mathrm{Ca}_{2} \mathrm{SiO}_{4}$ and $\mathrm{Sr}_{2} \mathrm{SiO}_{4}$ with crystal structure symmetry constraints. Experimental values (Refs. 2, 3,9) are given in parentheses.

\begin{tabular}{|c|c|c|c|}
\hline Crystal/Space group & $\gamma-\mathrm{Ca}_{2} \mathrm{SiO}_{4} / P c m n$ & $\beta-\mathrm{Ca}_{2} \mathrm{SiO}_{4} / P 2_{1} / n$ & $\beta-\mathrm{Sr}_{2} \mathrm{SiO}_{4} / P 2_{1} / n$ \\
\hline$a(\AA)$ & $4.9922(5.091)$ & $5.4957(5.502)$ & $5.6398(5.663)$ \\
\hline$b(\AA)$ & $6.8037(6.782)$ & $6.7710(6.745)$ & $7.0487(7.084)$ \\
\hline$c(\AA)$ & $11.2893(11.371)$ & $9.2371(9.297)$ & $9.5890(9.767)$ \\
\hline$\beta$ & & $94.17^{\circ}\left(94.59^{\circ}\right)$ & $93.39^{\circ}\left(92.67^{\circ}\right)$ \\
\hline$x / a$ of $\mathrm{Ca}(1) / \mathrm{Sr}(1)$ & & $0.2750(0.2738)$ & $0.2705(0.2618)$ \\
\hline$y / b$ of $\mathrm{Ca}(1) / \mathrm{Sr}(1)$ & & $1.3390(1.3428)$ & $0.3375(0.3425)$ \\
\hline$z / c$ of $\mathrm{Ca}(1) / \mathrm{Sr}(1)$ & & $0.5750(0.5694)$ & $0.5795(0.5778)$ \\
\hline$x / a$ of $\mathrm{Ca}(2) / \mathrm{Sr}(2)$ & $-0.0127(-0.011)$ & $0.2817(0.2798)$ & $0.2774(0.2698)$ \\
\hline$y / b$ of $\mathrm{Ca}(2) / \mathrm{Sr}(2)$ & & $1.0010(0.9976)$ & $0.0039(0.0007)$ \\
\hline$z / c$ of $\mathrm{Ca}(2) / \mathrm{Sr}(2)$ & $0.2806(0.280)$ & $0.3002(0.2981)$ & $0.3026(0.3023)$ \\
\hline$x / a$ of $\mathrm{Si}$ & $0.4336(0.427)$ & $0.2321(0.2324)$ & $0.2384(0.2427)$ \\
\hline$y / b$ of $\mathrm{Si}$ & & $0.7737(0.7814)$ & $-0.2286(-0.2219)$ \\
\hline$z / c$ of $\mathrm{Si}$ & $0.0959(0.098)$ & $0.5816(0.5817)$ & $0.5815(0.5813)$ \\
\hline$x / a$ of $\mathrm{O}(1)$ & $-0.2384(-0.262)$ & $0.2861(0.2864)$ & $0.2864(0.280)$ \\
\hline$y / b$ of $\mathrm{O}(1)$ & & $1.0059(1.0135)$ & $-0.0030(0.008)$ \\
\hline$z / c$ of $\mathrm{O}(1)$ & $0.0932(0.086)$ & $0.5613(0.5599)$ & $0.5693(0.571)$ \\
\hline$x / a$ of $\mathrm{O}(2)$ & $0.3025(0.302)$ & $0.0170(0.0202)$ & $0.0196(0.023)$ \\
\hline$y / b$ of $\mathrm{O}(2)$ & & $0.7452(0.7492)$ & $-0.2660(-0.274)$ \\
\hline$z / c$ of $\mathrm{O}(2)$ & $-0.0386(-0.042)$ & 0.6934 (0.6919) & $0.6824(0.675)$ \\
\hline$x / a$ of $\mathrm{O}(3)$ & $0.3053(0.292)$ & $0.4851(0.4859)$ & $0.4822(0.488)$ \\
\hline$y / b$ of $\mathrm{O}(3)$ & $0.0554(0.059)$ & $0.6595(0.6682)$ & $-0.3353(-0.321)$ \\
\hline$z / c$ of $\mathrm{O}(3)$ & $0.1618(0.163)$ & $0.6375(0.6381)$ & $0.6409(0.642)$ \\
\hline$x / a$ of $\mathrm{O}(4)$ & & $0.1529(0.1558)$ & $0.1755(0.191)$ \\
\hline$y / b$ of $\mathrm{O}(4)$ & & $0.6684(0.6710)$ & $-0.3234(-0.321)$ \\
\hline$z / c$ of $\mathrm{O}(4)$ & & $0.4254(0.4264)$ & $0.4272(0.431)$ \\
\hline
\end{tabular}




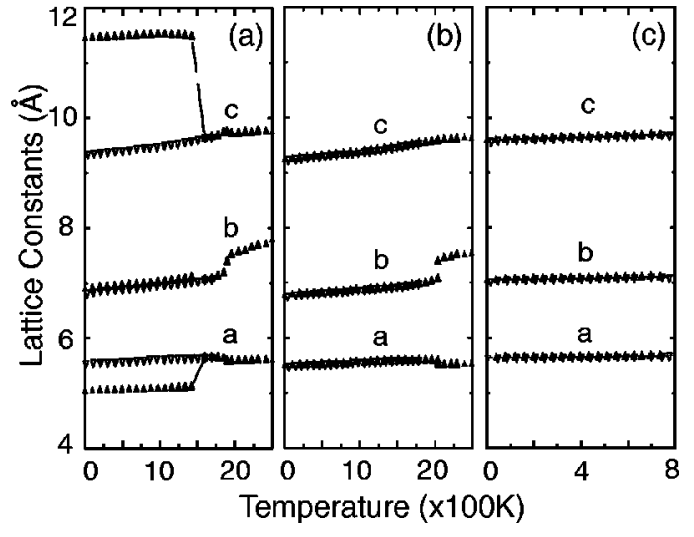

FIG. 2. Lattice constants of the unit cell as a function of temperature for the MD run. (a) $\mathrm{Ca}_{2} \mathrm{SiO}_{4}$, starting from phase $\gamma$, (b) $\mathrm{Ca}_{2} \mathrm{SiO}_{4}$, starting from phase $\beta$; (c) $\mathrm{Sr}_{2} \mathrm{SiO}_{4}$. Solid up triangles: heating up; hollow down triangles: cooling down.

that our potentials provide a good representation of the interactions in the alkaline-earth silicates under investigation.

\section{MOLECULAR DYNAMIC SIMULATIONS OF THE PHASE TRANSITIONS}

Our molecular dynamics simulations started from supercells of the relaxed theoretical structures. The supercells with 336 ions for $\mathrm{Ca}_{2} \mathrm{SiO}_{4}$ and $\mathrm{Sr}_{2} \mathrm{SiO}_{4}$ were formed by doubling the unit cells of the $\gamma$ or $\beta$ phase in the $a$ and $c$ directions and tripling in the $b$ direction. They were large enough to allow all possible phase transitions to occur. The simulations follow a constant- (zero-) pressure algorithm. ${ }^{19}$ Threedimensional periodic boundary conditions were employed to provide an infinite-size lattice. To make the simulations as realistic as possible, no restriction was applied (besides the periodic boundary condition) to the supercells, i.e., all of the ion positions and all of the lattice vectors were allowed to change during the simulations. Again, the long-range Coulomb interaction energies were calculated by the standard technique of the Ewald sum. ${ }^{18}$ At each temperature the average of the ion positions, energy, etc., were taken over $10 \mathrm{ps}$ using a $1 \mathrm{fs}$ molecular dynamics time step.

\section{A. Phase transition in $\mathrm{Ca}_{2} \mathrm{SiO}_{4}$}

The $\gamma$ phase is the most stable structure of $\mathrm{Ca}_{2} \mathrm{SiO}_{4}$ at room temperature. We first heated up the supercell of the $\gamma$ phase to high temperature and then cooled it down. Figures 2(a) and 3(a) show the lattice constants of the unit cell and the angle between $a$ and $c$ axes as a function of temperature on both heating and cooling. Clearly, at least two phase transitions take place on heating according to the abrupt changes of lattice constants at the transitions. In order to monitor how the structure transforms, we present projections of average structures at different temperatures in Figs. 4 and 5. In the plot the lines connect the oxygen atoms with the nearest oxygen atoms to form tetrahedra and the ovals centered about the atoms represent "thermal ellipsoids" which indicate the root-mean-square (rms) deviations of atoms from their average positions. We find that in our simulation the $\gamma$ phase transforms directly to the $\alpha_{H}^{\prime}$ phase at $1432 \mathrm{~K}$, and

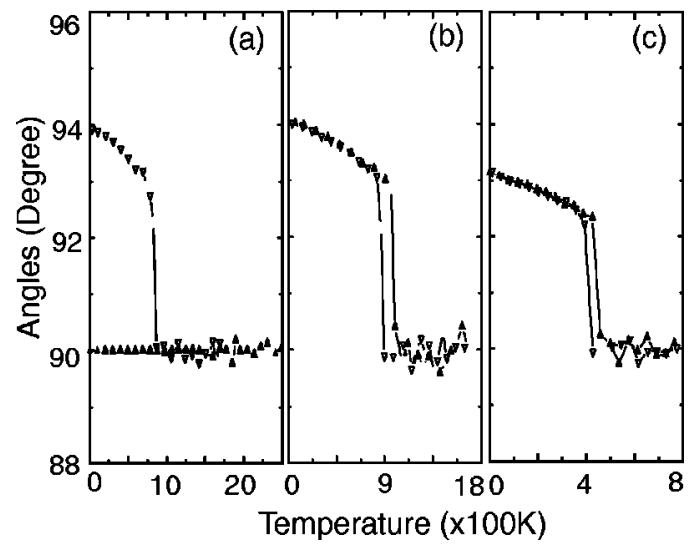

FIG. 3. Angle between lattice vectors $a$ and $c$ as a function of temperature for the MD run. (a) $\mathrm{Ca}_{2} \mathrm{SiO}_{4}$, starting from phase $\gamma$, (b) $\mathrm{Ca}_{2} \mathrm{SiO}_{4}$, starting from phase $\beta$; (c) $\mathrm{Sr}_{2} \mathrm{SiO}_{4}$. Solid up triangles: heating up; hollow down triangles: cooling down.

then to the $\alpha$ phase at $1851 \mathrm{~K}$. The $\alpha_{L}^{\prime}$ phase is supposed to appear between the $\gamma$ and $\alpha_{H}^{\prime}$ phases, but it is skipped in our simulation because of the drastic reconstruction in the transition. On cooling from the $\alpha_{H}^{\prime}$ phase, it first transforms into the $\alpha_{L}^{\prime}$ phase at $1283 \mathrm{~K}$, and then into the metastable $\beta$ phase at $826 \mathrm{~K}$. This phase transition sequence is exactly the same as that observed experimentally. In the transitions $\alpha_{H^{-}}^{\prime} \alpha_{L}^{\prime}$ and $\alpha_{L}^{\prime}-\beta$ the lattice constants change continuously on cooling, but the angle between the $a$ and $c$ axes jumps to $92.3^{\circ}$ from $90^{\circ}$ at the $\alpha_{L}^{\prime}-\beta$ transition [Fig. 3(a)]. Although the lattice constant $b$ of the $\alpha_{L}^{\prime}$ phase is tripled (see below), the parameters of the simplest unit-cell are reported in Fig. 2 for the sake of graphical continuity.

Starting from the supercell of the $\beta$ phase we observed the same sequence of phase transformations as in experiment on heating. Specifically, the $\beta$ phase first transforms into the $\alpha_{L}^{\prime}$ phase at $954 \mathrm{~K}$, then, to the $\alpha_{H}^{\prime}$ phase at $1580 \mathrm{~K}$, finally to the $\alpha$ phase at $1950 \mathrm{~K}$. On cooling the sequence of the phase transition is reversed. The lattice constants and the angle between the $a$ and $c$ axes as a function of temperature are presented in Fig. 2(b) and Fig. 3(b), respectively. The

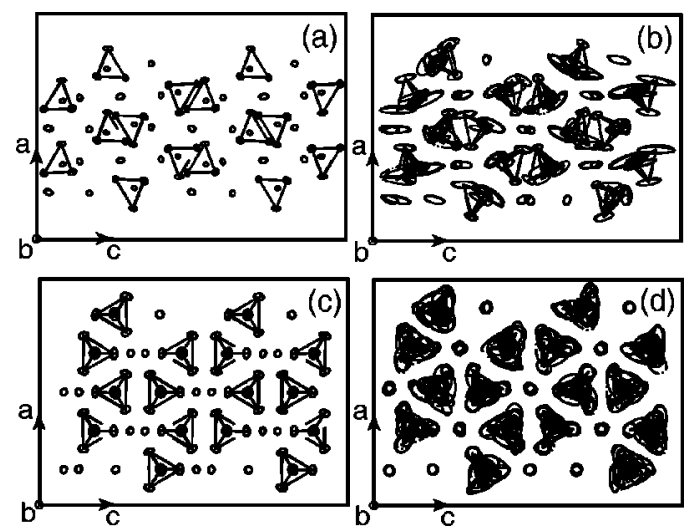

FIG. 4. Projections of the atomic positions along the $b$ axis in the average structure of $\mathrm{Ca}_{2} \mathrm{SiO}_{4}$ obtained from heating up the phase $\gamma$. (a) Phase $\gamma$ at $1000 \mathrm{~K}$, (b) phase $\gamma$ at $1390 \mathrm{~K}$, (c) phase $\alpha_{H}^{\prime}$ at $1600 \mathrm{~K}$, (d) phase $\alpha$ at $1870 \mathrm{~K}$. 

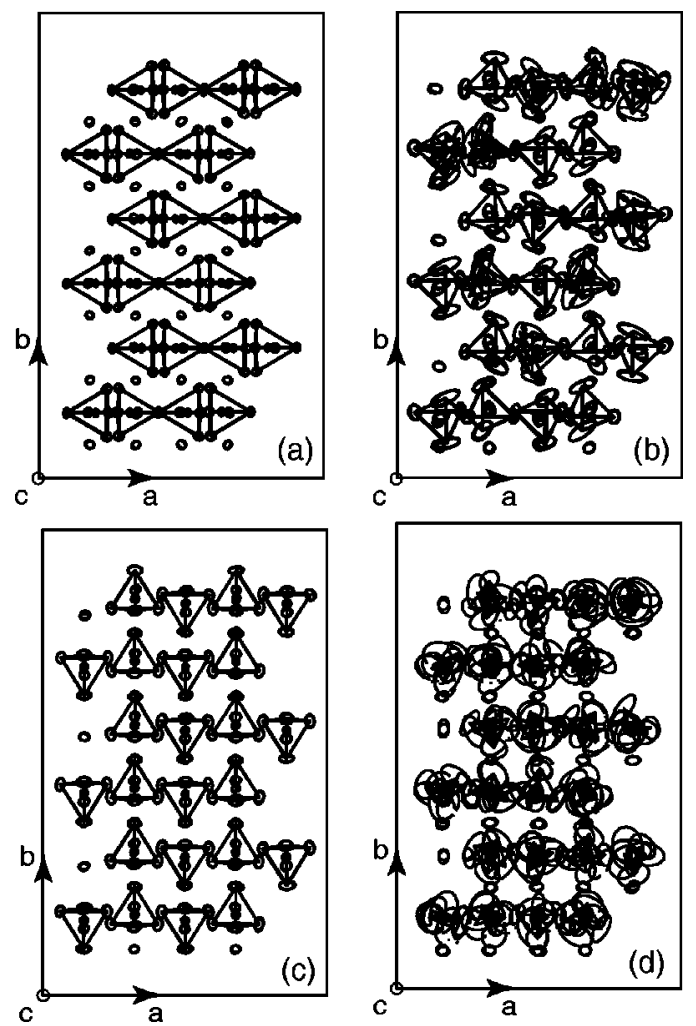

FIG. 5. Projections of the atomic positions along the $c$ axis in the average structure of $\mathrm{Ca}_{2} \mathrm{SiO}_{4}$ obtained from heating up the phase $\gamma$. (a) Phase $\gamma$ at $1000 \mathrm{~K}$, (b) phase $\gamma$ at $1390 \mathrm{~K}$, (c) phase $\alpha_{H}^{\prime}$ at $1600 \mathrm{~K}$, (d) phase $\alpha$ at $1870 \mathrm{~K}$.

projections of average structures obtained from heating up the $\beta$ phase are shown in Figs. 6 and 7.

From the discontinuous changes of lattice constants or angles between lattice vectors, we conclude that the transitions $\gamma-\alpha_{H}^{\prime}, \beta-\alpha_{L}^{\prime}$, and $\alpha_{H^{-}}^{\prime} \alpha$ are first order, while transition $\alpha_{L}^{\prime}-\alpha_{H}^{\prime}$ is second order.

\section{B. Phase transition in $\mathrm{Sr}_{2} \mathrm{SiO}_{4}$}

The $\beta$ phase is the most stable for $\mathrm{Sr}_{2} \mathrm{SiO}_{4}$. Starting from the $\beta$ phase, the phase transition sequence in $\mathrm{Sr}_{2} \mathrm{SiO}_{4}$ observed in our simulation is the same as that for $\mathrm{Ca}_{2} \mathrm{SiO}_{4}$ starting from the $\beta$ phase. The $\beta$ phase first transforms into the $\alpha_{L}^{\prime}$ phase at $425 \mathrm{~K}$, then, to the $\alpha_{H}^{\prime}$ phase at $790 \mathrm{~K}$. The $\alpha_{H}^{\prime}$ phase does not transform to the $\alpha$ phase at high temperature. On cooling from the $\alpha_{H}^{\prime}$ phase the sequence of phase transitions is reversed. The lattice constants and the angle between the $a$ and $c$ axes as a function of temperature are shown in Figs. 2(c) and 3(c), respectively. The projections of the average structures at different temperatures are similar to those in Figs. 6 and 7.

\section{DISCUSSION}

Barbier et al. studied the cation arrays and the orientational relations between phases $\alpha^{\prime}, \beta$, and $\gamma$ polymorphs of $\mathrm{Ca}_{2} \mathrm{SiO}_{4}$. They suggested that the phase transformation mechanism for $\beta-\gamma$ is displacive, while the phase $\alpha^{\prime} / \beta$ relation is a small topological distortion. ${ }^{20}$ Hyde et al. investigated the transition between the $\alpha^{\prime}$ phase and the $\beta$ phase of
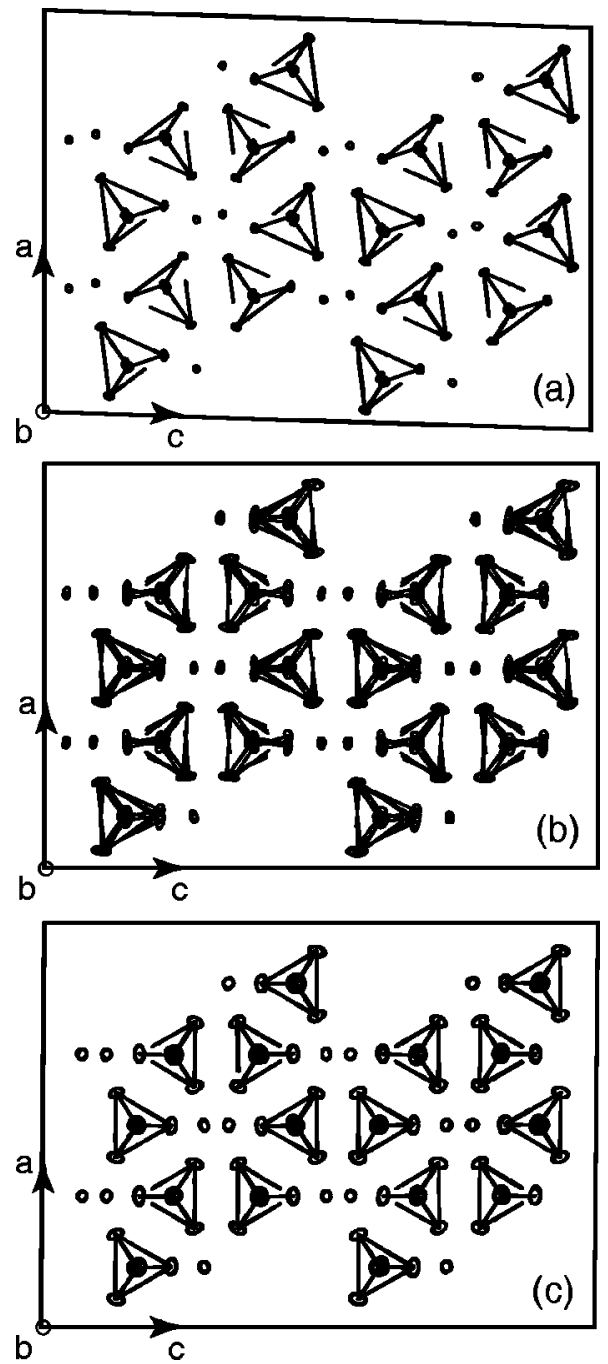

FIG. 6. Projections of the atomic positions along the $b$ axis in the average structure of $\mathrm{Ca}_{2} \mathrm{SiO}_{4}$ obtained from heating up the phase $\beta$. (a) Phase $\beta$ at $850 \mathrm{~K}$, (b) phase $\alpha_{L}^{\prime}$ at $1050 \mathrm{~K}$, (c) phase $\alpha_{H}^{\prime}$ at $1630 \mathrm{~K}$.

$\mathrm{Sr}_{2} \mathrm{SiO}_{4}{ }^{21}{ }^{21}$ Il'inets et al. suggested that the phase transitions $\alpha-\alpha_{H}^{\prime}$ and $\beta-\gamma$ were reconstructive, while $\alpha_{H^{-}}^{\prime} \alpha_{L}^{\prime}$ and $\alpha_{L}^{\prime}-\beta$ were displacive. ${ }^{22}$

The $\alpha$ phase appears at $1698 \mathrm{~K}$ in experiment. Its structure is still uncertain because it is not easy to access. Two models are proposed in the literature. In one model, the $\alpha$ phase has the space group $P 6_{3} m c$ in which all the $\mathrm{SiO}_{4}$

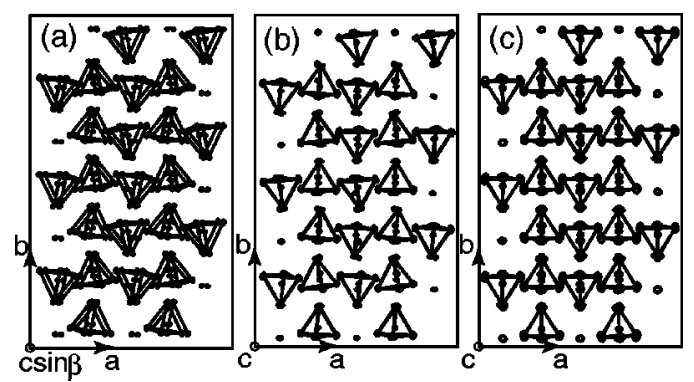

FIG. 7. Projections of the atomic positions along the $c$ axis in the average structure of $\mathrm{Ca}_{2} \mathrm{SiO}_{4}$ obtained from heating up the phase $\beta$. (a) Phase $\beta$ at $850 \mathrm{~K}$, (b) phase $\alpha_{L}^{\prime}$ at $1050 \mathrm{~K}$, (c) phase $\alpha_{H}^{\prime}$ at $1630 \mathrm{~K}$. 
tetrahedra have one apex pointing in the same direction, ${ }^{8}$ while in the other model, the space group is $P 3 m 1$ and the $\mathrm{SiO}_{4}$ tetrahedra alternately have two opposite orientations. ${ }^{7}$ Il'inets et al. obtained the $\alpha$ phase of $\mathrm{Ca}_{2} \mathrm{SiO}_{4}$ at room temperature by replacing $40 \%-45 \%$ of the $\mathrm{Ca}$ by $\mathrm{Ba}$. The refined crystal structure of this mixed crystal has space group $\mathrm{Pb}_{3} m c{ }^{23}$

One can see from Figs. 4(d) and 5(d) that the phase $\alpha$ has a disordered structure. The $\mathrm{SiO}_{4}$ tetrahedra not only make librations at their equilibrium position about the orthorhombic $b$ axis, which is parallel to the hexagonal $c$ axis, but also jump $\pm 120^{\circ}$ to their equivalent sites. Also, the $\mathrm{SiO}_{4}$ tetrahedra make large rotation about the orthorhombic $a$ and $c$ axes. This means that the $\alpha-\mathrm{Ca}_{2} \mathrm{SiO}_{4}$ structure is in dynamical equilibrium, i.e., the tetrahedra do not have a fixed position but oscillate with large amplitudes. This kind of disordered phase is isostructural to the high temperature phase of $\mathrm{K}_{2} \mathrm{SO}_{4}{ }^{24}$ Hence, we believe that the $\alpha$ phase of $\mathrm{Ca}_{2} \mathrm{SiO}_{4}$ has the same space group $P 6_{3} / \mathrm{mmc}$ as that of hightemperature phase of $\mathrm{K}_{2} \mathrm{SO}_{4}$, It can also be seen from Figs. 4(c) and 5(c) that the $\alpha_{H}^{\prime}$ phase is isostructural to the $\beta-\mathrm{K}_{2} \mathrm{SO}_{4}$. Thus the phase transition mechanism between the $\alpha_{H}^{\prime}$ phase and the $\alpha$ phase in $\mathrm{Ca}_{2} \mathrm{SiO}_{4}$ is similar to the hightemperature phase transition in $\mathrm{K}_{2} \mathrm{SO}_{4} \cdot{ }^{24}$ Specifically, the phase transition is first-order and order-disorder type that involves the displacements of the $\mathrm{Ca}$ and $\mathrm{SiO}_{4}$ ions and orientational disorders of the $\mathrm{SiO}_{4}$ ions.

The structure of $\alpha_{L}^{\prime}$ phase is generally believed to be a superstructure of the $\alpha_{H}^{\prime}$ phase, but the exact nature of the superstructure has not yet been established. Barnes et al. reported a $2 a \times b \times 2 c$ superstructure from X-ray powder data, ${ }^{4}$ whereas Saaldeld et al. observed an $a \times 3 b \times c$ superstructure by means of high-temperature single-crystal $x$-ray diffraction. ${ }^{5}$ Remy et al. found they could index their x-ray powder diffraction data using both superstructures above. ${ }^{1}$ From the projections of the average structures of the $\alpha_{L}^{\prime}$ and $\alpha_{H}^{\prime}$ phases shown in Figs. 6(b), 6(c) and 7(b), 7(c), we find that the transition $\alpha_{H^{-}}^{\prime} \alpha_{L}^{\prime}$ is due to tilting of the $\mathrm{SiO}_{4}$ tetrahedra. In the $\alpha_{H}^{\prime}$ phase, there are mirror planes passing through the $\mathrm{SiO}_{4}$ tetrahedra at $x=1 / 4$ and 3/4 levels and perpendicular to the $a$ axis [Fig. 6(c)]. In the $\alpha_{L}^{\prime}$ phase the $\mathrm{SiO}_{4}$ tetrahedra are tilted so that mirror planes, corresponding to those in the phase $\alpha_{H}^{\prime}$, are missing. Then, the structure of the $\alpha_{L}^{\prime}$ phase is tripled along the $b$ axis [Figs. 6(b) and 7(b)] because of tilting of the $\mathrm{SiO}_{4}$ tetrahedra. Thus our simulations support the conclusions of Saaldeld et al. that the $\alpha_{L}^{\prime}$ phase is an $a \times 3 b \times c$ superstructure of the $\alpha_{H}^{\prime}$ phase and the transition $\alpha_{H^{-}}^{\prime} \alpha_{L}^{\prime}$ is caused by a tilting of $\mathrm{SiO}_{4}$ tetrahedra. ${ }^{5}$ The phase transition is second order and involves small displacement of $\mathrm{Ca}$ and $\mathrm{SiO}_{4}$ ions in addition to the slight tilting of the $\mathrm{SiO}_{4}$ ions.

One can see from Figs. 6 and 7 that the $\beta$ phase is also closely related to the $\alpha_{L}^{\prime}$ and $\alpha_{H}^{\prime}$ phases. The transition $\alpha_{L}^{\prime}-\beta$ is due to a further tilting of the $\mathrm{SiO}_{4}$ tetrahedra and a larger displacement of the $\mathrm{Ca}$ ions. This phase transition can be thought of as displacive.

The transition $\gamma-\alpha_{H}^{\prime}$ involves the large displacements of $\mathrm{Ca}$ and $\mathrm{SiO}_{4}$ ions and large rotations of the $\mathrm{SiO}_{4}$ ions. Figures 4(b) and 5(b) show the average structure of the $\gamma$ phase just below the transition. Large ovals around the atoms indicate that the $\mathrm{SiO}_{4}$ tetrahedra are in rotation. In this process, some $\mathrm{Ca}-\mathrm{O}$ bonds are broken and new $\mathrm{Ca}-\mathrm{O}$ bonds are formed. We think the phase transition is likely reconstructive.

We did not obtain the $\beta$ - $\gamma$ phase transformation in our simulation. However, we can get the orientation relationships between them from the orientation relationships between the $\gamma$ and $\alpha_{H}^{\prime}, \beta$, and $\alpha_{H}^{\prime}$ phases. This can be summarized to the following manner: $\quad(100)_{\beta}\left\|(100)_{\gamma}, \quad(010)_{\beta}\right\|(010)_{\gamma}$, $\perp(001)_{\beta} \|(001)_{\gamma}$. Gazzoni et al. studied the crystallographic relations and the transition mechanism between the $\beta$ and $\gamma$ phases in detail. ${ }^{25}$

With respect to the phase transition in $\mathrm{Sr}_{2} \mathrm{SiO}_{4}$, an incommensurate phase was found in experiment between the $\beta$ and $\alpha^{\prime}$ phases. ${ }^{10}$ In our simulation the $\beta$ and $\alpha^{\prime}$ phases are isostructural to the $\beta$ and $\alpha_{H}^{\prime}$ phases of $\mathrm{Ca}_{2} \mathrm{SiO}_{4}$, respectively. Because we cannot simulate the incommensurate phase due to the periodic boundary conditions, we believe that the $\alpha_{L}^{\prime}$ phase we obtained in our simulation, which is a tripled superstructure of the $\alpha^{\prime}$ phase, is a lock-in from the incommensurate phase. Hyde et al. argued that the $a \times 3 b$ $\times c$ superstructure of $\mathrm{Ca}_{2} \mathrm{SiO}_{4}$ also probably corresponds to a modulated structure, with a periodicity close to (rather than exactly) $3 \times b \cdot{ }^{21}$ If it is right, the phase $\alpha_{L}^{\prime}$ of $\mathrm{Ca}_{2} \mathrm{SiO}_{4}$ in our simulation will be a lock-in as well.

\section{CONCLUSION}

By using the potentials calculated from the Gordon-Kim modified electron gas formalism extended to molecular ions, we successfully reproduced the polymorphic transitions in $\mathrm{Ca}_{2} \mathrm{SiO}_{4}$ and $\mathrm{Sr}_{2} \mathrm{SiO}_{4}$. We find that the $\alpha_{H}^{\prime}$ phase of $\mathrm{Ca}_{2} \mathrm{SiO}_{4}$ and the $\alpha^{\prime}$ phase of $\mathrm{Sr}_{2} \mathrm{SiO}_{4}$ have the $\beta-\mathrm{K}_{2} \mathrm{SO}_{4}$ structure. The $\alpha_{L}^{\prime}$ phase of $\mathrm{Ca}_{2} \mathrm{SiO}_{4}$ is an $a \times 3 b \times c$ superstructure of the $\alpha_{H}^{\prime}$ phase. The $\alpha$ phase of $\mathrm{Ca}_{2} \mathrm{SiO}_{4}$ is an orientationally disordered structure with space group $\mathrm{P}_{3} / \mathrm{mmc}$.

\section{ACKNOWLEDGMENTS}

This work was supported by the U.S. Army Research Office under Grants Nos. DAAG 55-97-1-0106 and DAAG 55-98-1-0273. The computer facility was supported by Nebraska-EPSCoR-NSF Grant EPS-9720643.

${ }^{1}$ C. Remy and D. Andrault, J. Am. Ceram. Soc. 80, 851 (1997).

${ }^{2}$ D. K. Smith, A. Majumdar, and F. Ordway, Acta Crystallogr., Sect. B: Struct. Crystallogr. Cryst. Chem. 18, 787 (1965).

${ }^{3}$ K. H. Jost, B. Ziemer, and R. Seydel, Acta Crystallogr., Sect. B: Struct. Crystallogr. Cryst. Chem. 33, 1696 (1977).

${ }^{4}$ P. Barnes, C. H. Fentiman, and J. W. Jeffery, Acta Crystallogr., Sect. A: Cryst. Phys., Diffr., Theor. Gen. Crystallogr. 36, 353 (1980).

${ }^{5}$ R. Saaldeld, Am. Mineral. 60, 824 (1975).

${ }^{6}$ A. M. Il'inets and M. Y. Bikbau, Sov. Phys. Crystallogr. 35, 54 (1990).

${ }^{7}$ M. A. Bredig, J. Am. Ceram. Soc. 33, 188 (1950).

${ }^{8}$ W. Eysel and T. Hahn, Z. Kristallogr. 131, 322 (1970).

${ }^{9}$ M. Catti, G. Gazzoni, and G. Ivaldi, Acta Crystallogr., Sect. C: Cryst. Struct. Commun. 39, 29 (1983)

${ }^{10}$ R. L. Withers, B. G. Hyde, and J. G. Thompson, J. Phys. C 20, 1653 (1987).

${ }^{11}$ R. G. Gordon and Y. S. Kim, J. Chem. Phys. 56, 3122 (1972).

${ }^{12}$ H. M. Lu and J. R. Hardy, Phys. Rev. B 42, 8339 (1990).

${ }^{13}$ M. J. Frisch, A. Frisch, and J. B. Foresman, Gaussian94, Gaussian, Inc., Pittsburgh, PA, 1994. 
${ }^{14}$ H. B. Schlegel, J. Comput. Chem. 3, 214 (1982).

${ }^{15}$ R. S. Mulliken, J. Chem. Phys. 23, 1833 (1955).

${ }^{16}$ E. Clementi and C. Roetti, At. Data Nucl. Data Tables 14, 177 (1974)

${ }^{17}$ D. A. Liberman, D. T. Cromer, and J. T. Waber, Comput. Phys. Commun. 2, 107 (1971).

${ }^{18}$ N. Karasawa and W. A. Goddard, J. Phys. Chem. 93, 7320 (1989).

${ }^{19}$ M. Parinello and A. Rahman, Phys. Rev. Lett. 45, 1196 (1980).

${ }^{20}$ J. Barbier and B. G. Hyde, Acta Crystallogr., Sect. B: Struct. Sci. 41, 383 (1985).
${ }^{21}$ B. Hyde, J. R. Seller, and L. Stenberg, Acta Crystallogr., Sect. B: Struct. Sci. 42, 423 (1986)

${ }^{22}$ A. M. Il'inets and M. Y. Bikbau, Sov. Phys. Crystallogr. 35, 50 (1990).

${ }^{23}$ A. M. Il'inets and M. Y. Bikbau, Sov. Phys. Crystallogr. 34, 677 (1989).

${ }^{24}$ H. Arnold, W. Kurtz, A. Richter-Zinnius, J. Bethke, and G. Heger, Acta Crystallogr., Sect. B: Struct. Sci. 37, 1643 (1981).

${ }^{25}$ G. Gazzoni and G. Chiari, Acta Crystallogr., Sect. B: Struct. Sci. 42, 146 (1986). 